\title{
Mobility Driver Changes in Metropolitan Cities: a Case Study
}

\author{
Maurizio Arnone ${ }^{1, a}$, Tiziana Delmastro ${ }^{1, b}$ and Letizia Saporito ${ }^{1, c}$ \\ ${ }^{1}$ SiTI - Higher Institute on Territorial Systems for Innovation, Via P.C. Boggio 61, 10138, Turin, Italy \\ amaurizio.arnone@siti.polito.it, btiziana.delmastro@siti.polito.it, ${ }^{\mathrm{c}}$ etizia.saporito@siti.polito.it
}

Keywords: Metropolitan Cities, Mobility Drivers, Passenger Mobility Trends.

\begin{abstract}
The new proposed law aimed at reorganizing the Italian administrative territorial institutions, called "Delrio", has raised a big debate regarding the correct identification of the metropolitan cities and definition of their boundaries. This law states that basically the metropolitan city boundaries should correspond to the provincial ones. The present paper is aimed at contributing to this debate from a different point of view. Mobility is changing across the whole Europe, however different trends could be identified in different areas. Understanding this changes and the characteristics of the future mobility could support the stakeholders in the difficult process of identification of the new metropolitan cities boundaries.
\end{abstract}

\section{Introduction}

The first Italian law regarding the reorganization of administrative territorial institutions (L.142/1990) defined a metropolitan city as a core city with the surrounding towns strongly connected in terms of economic activities, essential public services, cultural relations and territorial features. The new "Delrio law", however, states that the metropolitan city boundaries should correspond to the provincial ones. This controversial choice has led to a discussion among various stakeholders, who highlighted the risks of applying the same institutional model to wide areas with big territorial, demographic, social, economic and mobility differences.

Twenty metropolitan cities have been identified: Turin, Milan, Venice, Genoa, Bologna, Florence, Rome, Bari, Naples [14], Reggio Calabria, Bergamo, Brescia, Salerno, the union of the provinces of Padua-Vicenza and of Verona-Treviso, the autonomous provinces of Cagliari, Catania, Messina, Palermo and Trieste. A very interesting example, among all these cities, is represented by the metropolitan city of Turin (the capital city of Piedmont) that should include 315 municipalities [3].

The present paper analyses the main changes in passenger mobility in the province of Turin area, to understand if the metropolitan city could coincide with its province.

In the first paragraph the main drivers affecting passenger mobility are identified and analysed to understand the big changes that they are bringing about in mobility. The second paragraph focuses this analysis on the Turin case study and investigates the main mobility drivers changes in different areas of the province. Then some conclusions regarding the correct identification of Turin metropolitan city boundaries are drawn.

\section{Main changes in factors affecting mobility}

The main transport drivers affecting passenger mobility demand have been derived from previous studies and analysis conducted at European level, in particular the TRANSvisions study [13] and the "EU transport GHG: Routes to 2050?" project [12].

The selected drivers are listed in Table 1, where their main areas of impact are also indicated. Similarly to drivers, the impact areas have also been identified integrating the main outcomes of the analysed studies with transport experts' opinions. Seven impact categories were used to describe how drivers can affect passenger transport demand: total number of trips (the overall transport volume); trip frequency (the number of trips per person or per household); trip purpose; trip distance; trip time (the time of day when the trips start); mode choice and route choice (only valid for road transport). 
The drivers affecting passenger mobility have been classified in seven groups (starting from the TRANSvisions classification), among the most significant there are:

- Demographic drivers: including population size, age distribution, migration and household type and size. The increasing population size entails an increasing mobility demand, but recent trends show that also population composition is changing and needs to be taken into account. The proportion of elderly people in Europe is already higher than that of children: above a certain age, people tend to travel less, moreover they travel for different purposes than young persons (e.g. leisure trips). This may result in an increase of demand for collective modes of transport, even if nowadays elderly people represent a larger share in driving population than in the past. On the other hand, the decreasing number of persons in the productive age category and their progressive substitution by immigrants, filling employment gaps especially in low skilled jobs, is affecting mobility patterns in terms of number and purpose of trips and choice of cheaper transport modes. The decreasing tendency of household size (single or two-person households are more and more diffused) is also concerning transport demand, leading to an increase in car ownership per capita, due to the reduced opportunity to share the same car among household members, and a higher number of car trips per person, since single people are more willing to travel for non-systematic purposes.

- Economic drivers: including macro-economic development, income, employment and globalization. Economic development and a higher disposable income generate new activities and opportunities for a better and wealthier lifestyle which lead people to move with more frequency and for many different purposes. Even if, thanks to increasing wealth and revenues, the number of trips carried out for different purposes is constantly increasing, commuting still represents an important share (almost 30-35\%) of passenger transport demand [5,6,7,9] and employment is still a very important mobility driver. The rising unemployment rate, generated by the economic downturn in the last years, saw the number of commuting trips decreasing; furthermore, due to the few job opportunities available, people are nowadays willing to accept an employment further away from their place of residence, thus affecting trip distances and trip times. Also innovative types of employments and contracts could play an important role in the change of commuters' mobility trends: the diffusion of part-time jobs will impact on the time of the day when people travel and teleworking will reduce the number of commuting trips. However there is still no large evidence of such changes and the debate concentrates on how the decreasing number of commuting trips due to home-based work, could be substituted by other types of trips: several studies demonstrated that people are disposed to spend a certain amount of their personal income (about 10-15\%) and of their time (about 1 hour per day) on travel [13].

Other possible drivers, with a minor impact on passenger mobility, include:

- Socio-cultural factors: the improvement of living standards has led to an increase in leisure time, thus rising transport demand and trip frequency. Due to the availability of spare-time and to new travel opportunities, tourism has also developed, leading to a shift of mobility demand to fast transport modes. Another increasing trend affecting mobility patterns is the rising consciousness of sustainability: the car is not seen as a status symbol anymore nor the only way to provide freedom of movement and the number of trips by means of walking, cycling and using public transport, has increased.

- Energy: as a consequence of the economic crisis and of the ever increasing oil prices, the price elasticity of demand with respect to fuel costs has increased, meaning that transport sensitivity to energy costs is higher than before and this resulted above all in road traffic reduction.

- Technologies: new developing fuel efficient engines will allow to improve many means of transport and to reduce trip costs thus enhancing the use of alternative modes. Through Intelligent Transport Systems diffusion (e.g. variable message signs, in-vehicle technology, route planners, etc.) trip quality is continuously being improved and the management and organization of trips has become easier. On the other hand, as a result of the continuous improvement in digital communication, an increasing number of activities can now be done through the Internet (e.g., on-site meetings can be substituted by online meetings; banks and 
universities can do much of their business online; e-shopping is continuously increasing) without the need of moving anymore (E-Everything).

- Transport infrastructures and services: the development of new infrastructures and transport services and the improvement of their level of service, accessibility and safety aspects, creates new and better opportunities for mobility which boost the trip frequency and distance and impact on route (for car trips) and mode choice. The choice of alternative transport modes and a reduction of car trips can be strongly affected by efficient integrated transport systems.

- Policies: transport and land use policies at European, national and local level are very important driving factors affecting transport since they have the possibility to change and act on the mobility drivers described above.

The effects on mobility of most of the previous emerging drivers (e.g. sustainable lifestyle, eeverything, ITS, safety, land policies) still need to be analysed more in depth: in many cases both trip reduction and generation effects may occur and people's sensitivity to such drivers still represent a knowledge gap.

Table 1. Drivers of passenger mobility demand and their main impacts

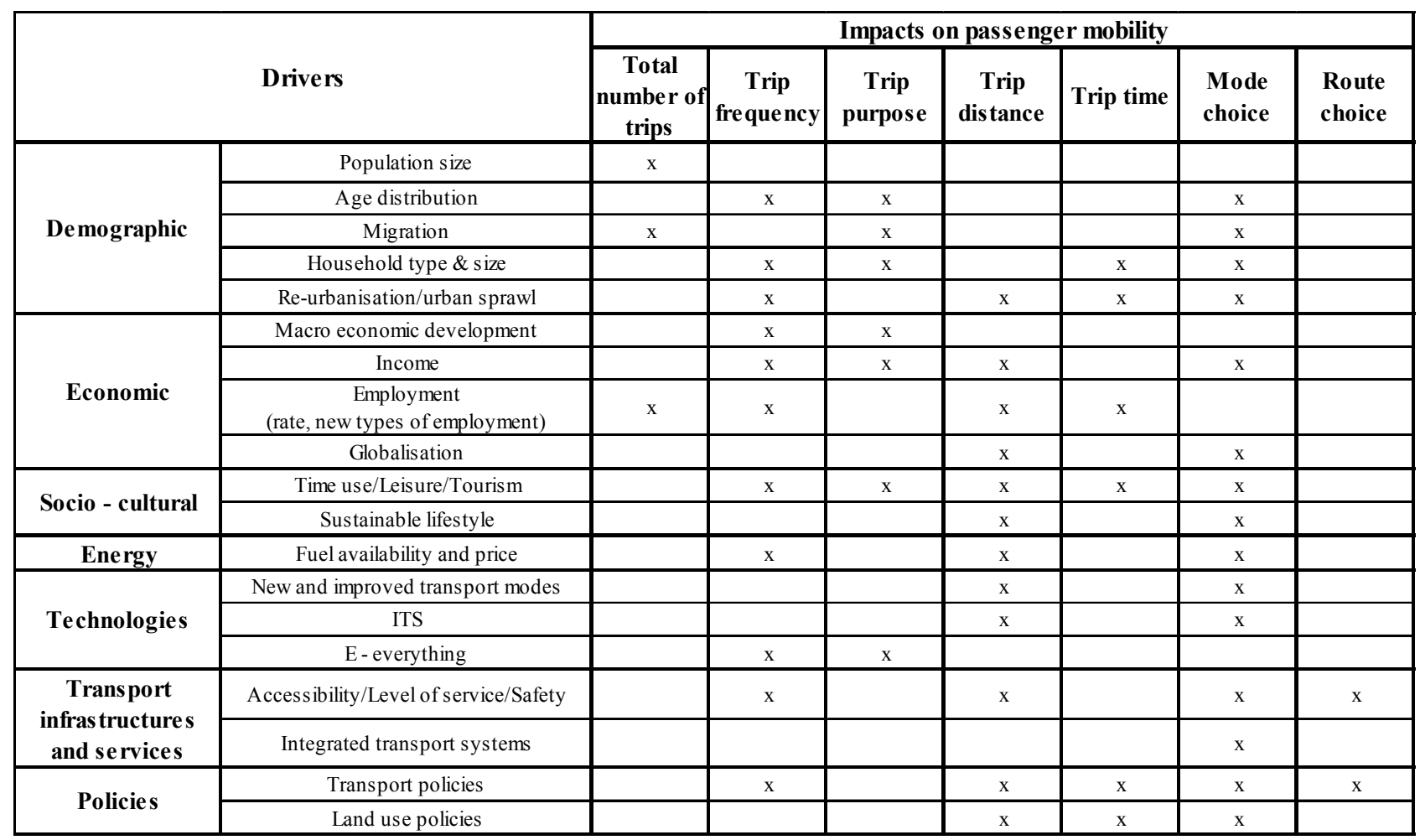

\section{Mobility drivers changes in the Province of Turin}

In order to understand if mobility drivers are changing in a different way in different areas, the most significant demographic drivers have been investigated focussing on the area of the Province of Turin. In particular three drivers have been analysed: the population size, the age distribution and the migration. The analysis was carried out through desk research and processing of data coming from different official sources, such as the national and regional statistical databases or regional mobility surveys.

Looking at aggregated provincial data, in the last ten years the trend of the population size has shown an annual increase of about $0,35 \%$ and this figure is expected to increase to $0,80 \%$ in the next ten years. Official forecasts report that in 2025 the number of inhabitants in the Province will be 2429956 , about $10 \%$ more than the current value. 
A significant increase of the over-65 population has been observed in the last 20 years with an annual average rate of about $1,8 \%$. This rate is foreseen to remain more or less constant $(1,9 \%)$, as a result in 2025 people over- 65 will become about $26 \%$ of total population.

On the other hand immigration of foreign people has contributed to compensate population aging. Immigrants have grown with an annual average rate of $12,7 \%$ since 2002 and, assuming a similar future increase rate, they will become about $36 \%$ of total population in 2025 .

However, this overall trend can vary significantly depending on the analysed areas, if we move from provincial to local level. The changes in the aforementioned drivers in the 2002-2012 time period are presented for each municipality of the Turin Province in the following figures.

Analysing the percentage change in population size between 2002 and 2012 (Fig. 1), two different zones can be identified: the area next to the mountains and to the borders which shows the most significant percentage of decrease in population size and the area of Turin and its surroundings, where the population has increased even more than $5 \%$ (especially in the municipalities around the city of Turin). This trend shows both the propensity of people to move from isolated areas to urban and suburban zones and the occurring urban sprawl phenomenon (a shift in the location of activities and residential areas towards the peripheries of urban agglomerations).

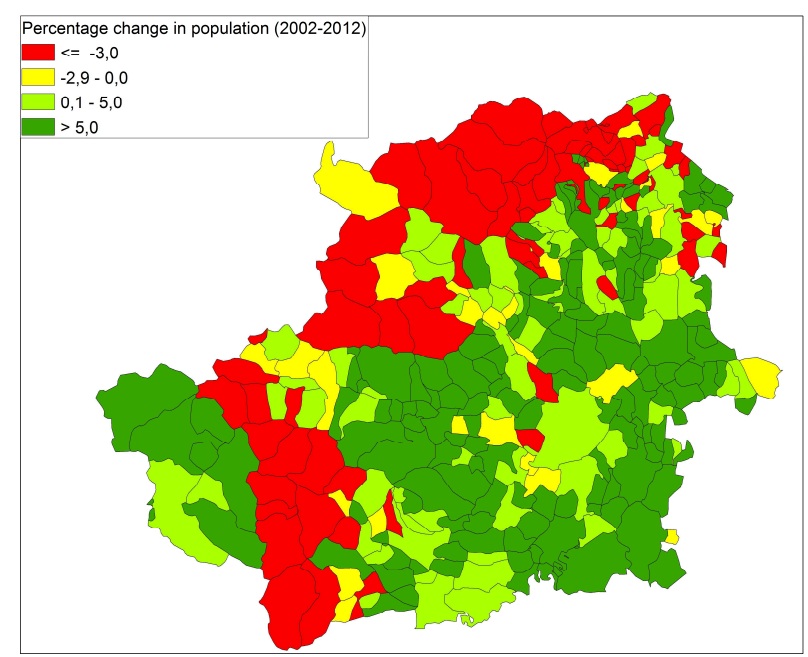

Fig. 1 Percentage change in population size between 2002 and 2012 (source Istat)

A distinction between the two different areas can be observed even looking at the variation of the ageing index (share of people over-65 on the total population) in the decade 2002-2012 (Fig. 2).

Even if in almost all the municipalities the population progressively aged, the index reaches values major than $30 \%$ in the mountain zone, while in the surroundings of Turin it is lower than $25 \%$.

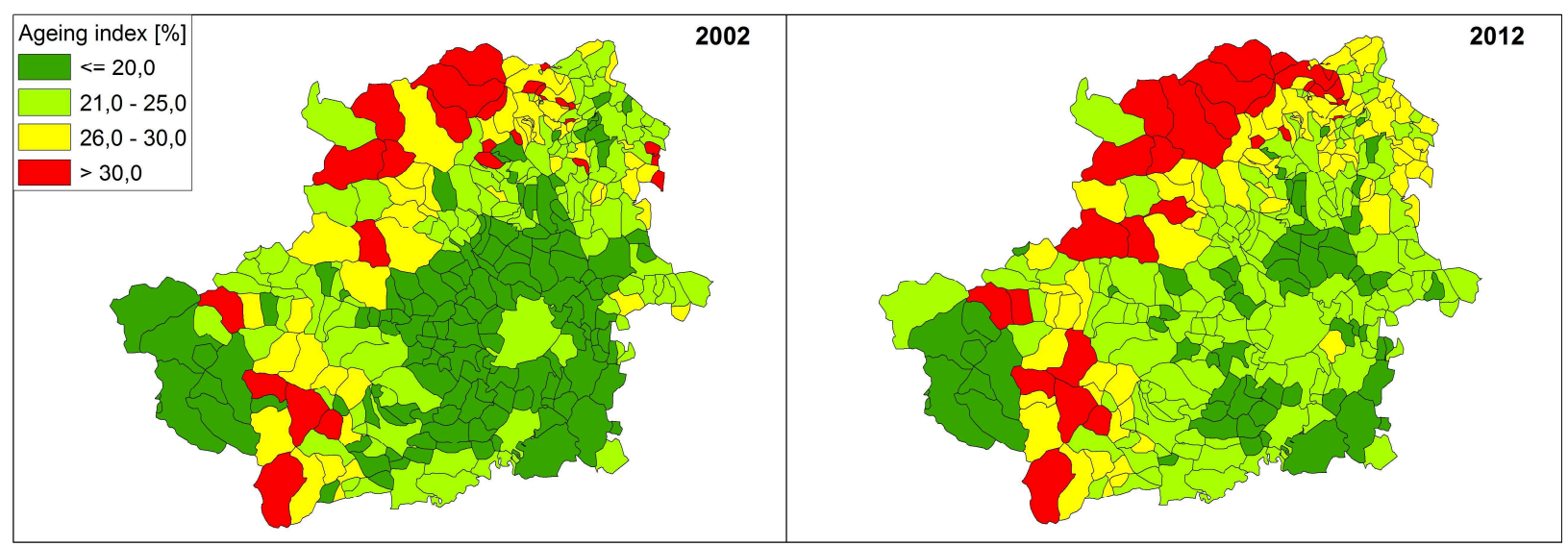

Fig. 2 Percentage of over 65 on total population in 2002 and 2012 (source Istat) 
A similar trend is evident when analysing the change in the number of foreign residents (Fig. 3): also this driver presents a different behaviour in the two identified zones, with a more significant increase of foreign population in the surrounding of Turin than in the mountain municipalities.

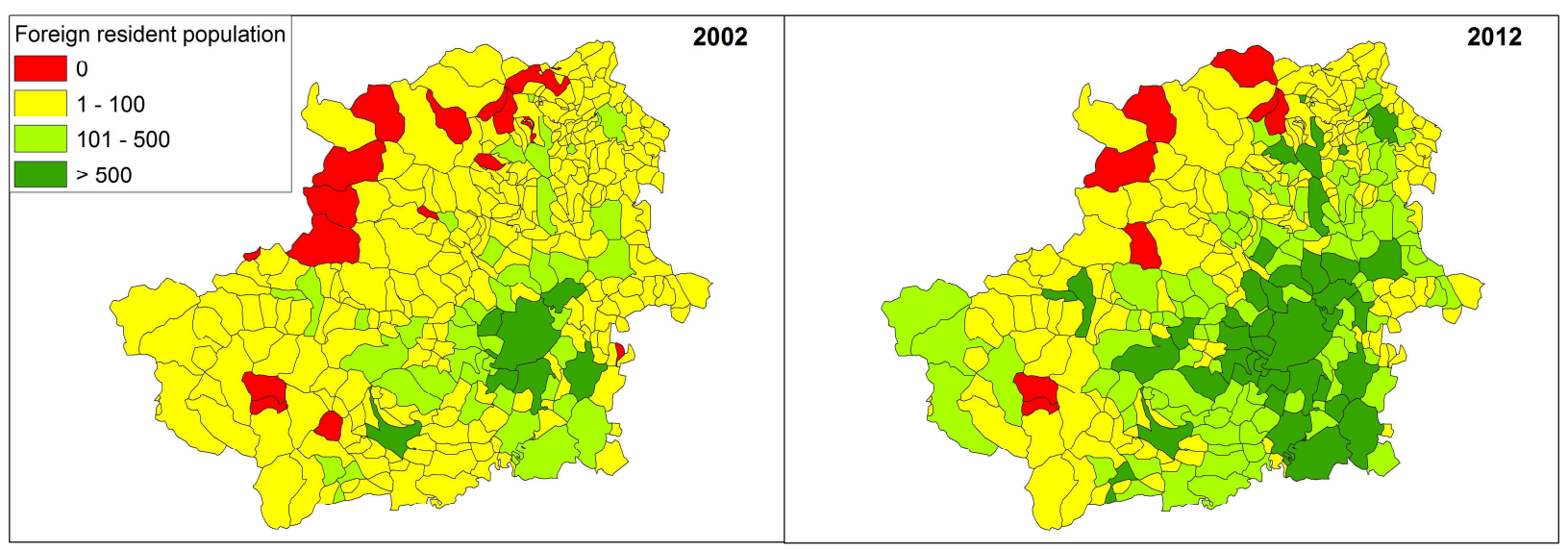

Fig. 3 Number of foreign resident in 2002 and in 2012 (source Istat)

These trends confirm the changes in mobility patterns that have been observed in the study area in the same time period $(2000-2010,[16,17])$ :

- with respect to the total passenger demand of the Province area, the share of demand generated and attracted by the Turin metropolitan area (including only the municipalities nearest to the core city) has increased from $68 \%$ to $71 \%$ while trips in the rest of the province have decreased;

- inside the metropolitan area, Turin still represents the most important attracting and generating node, but the quota of passenger flows from or to Turin has decreased from $81 \%$ to $77 \%$ while trips having both origin and destination in the Turin surroundings have increased from $19 \%$ to $23 \%$. This figures show that the municipalities around Turin are raising their importance as attracting and generating nodes and confirm the occurring urban sprawl phenomenon which is contributing to the progressive extension of the metropolitan area;

- considering trips generated or attracted by the rest of the province, inner trips have slightly decreased, while passenger flows from and towards the metropolitan area have shown a slight increase from $18.9 \%$ to $20.3 \%$; also in this case it's interesting to notice that the number of trips coming or going to the city of Turin diminished in favour of flows towards the suburban areas.

\section{Conclusions}

The trends of the most important demographic drivers affecting passenger mobility, observed in the province of Turin, as well as the last mobility demand trends, give a further example of how identifying a metropolitan city with its province area could arise difficulties in correctly managing all its needs. The Turin case study clearly show that a big area such a province can present many heterogeneities concerning not only different territorial features, but also many other aspects such as, for example, mobility behaviours. In particular at least two zones can be identified within the province of Turin:

- a mountain area where the population is steadily ageing and decreasing and

- a metropolitan zone, made up of the city of Turin and its surrounding municipalities, where, even if the number of elderly people is growing, their share on the total population remains lower than 25\%; moreover the population size is increasing thanks also to the rising number of immigrants who are settling especially in the suburban areas.

As well as mobility drivers, also passenger demand trends highlight the presence and the different needs of the two separate zones: 
- an outer zone where connections to the Turin metropolitan area (not only with the core city but also with the suburban municipalities) should be granted, without forgetting to provide inner accessibility for the growing elderly population and

- a metropolitan zone including Turin and its steadily widening surroundings where new residential areas and activities are settling down attracting increasing traffic flows: in such area transport measures to face arising congestion problems (e.g. widespread transport services linking the suburban municipalities) should be funded.

\section{Summary}

The present paper analysed the main demographic drivers affecting passenger mobility in the Province of Turin and confirmed that identifying a metropolitan city with its province area could rise difficulties in correctly managing all its needs.

The analysis led to the identification of at least two different areas with very diverse characteristics that should have separate institutional models.

\section{Acknowledgements}

We would like to thank our colleague C. Chietera for her contribution in producing the maps.

\section{References}

[1] L. Dijkstra, H. Poelman: Cities in Europe the new OECD-EC definition, European Commision, RF01/2012, (2012)

[2] CENSIS: Rileggere i territori per dare identità e governo all'area vasta. Il governo delle aree metropolitane in Europa, Report di ricerca, Roma (2014)

[3] Information on http://www.upinet.it

[4] L. 8 giugno 1990, n.142, in materia di "riforma degli enti locali"

[5] Department for Transport UK: Statistical Release - National travel survey 2010, (2011)

[6] Department for Transport UK: Statistical Release - National travel survey 2011, (2012)

[7] Department for Transport UK: Statistical Release - National travel survey 2012, (2013)

[8] Information on EC Eurostat http://epp.eurostat.ec.europa.eu

[9] Isfort: La domanda di mobilità degli italiani. Rapporto congiunturale di fine anno, (2011)

[10] T. Litman: The Future isn't what it used to be, Victoria Transport Policy Institute, (2013)

[11] OECD: Competitive cities in the global economy, OECD Territorial Reviews, (2006)

[12] C. Sessa, R. Enei - ISIS: EU Transport GHG: Routes to 2050? EU transport demand: Trends and drivers, project funded by the European Commission's Directorate- General Environment, (2009)

[13] TRANSvisions: Report on Transport Scenarios with a 20 and 40 Year Horizon, Project funded by the European Commission - DG TREN, Final Report, (2009)

[14] Information on http://www.interno.gov.it

[15] Information on http://demo.istat.it

[16] Agenzia Mobilità Metropolitana Torino: Indagine sulla mobilità delle persone e sulla qualità dei trasporti 2010 - Area Metropolitana e Provincia di Torino, (2011)

[17] Azienda Torinese Mobilità: Indagine sulla mobilità delle persone e sulla qualità dei trasporti 2010 nella Provincia di Torino 2000, (2001) 